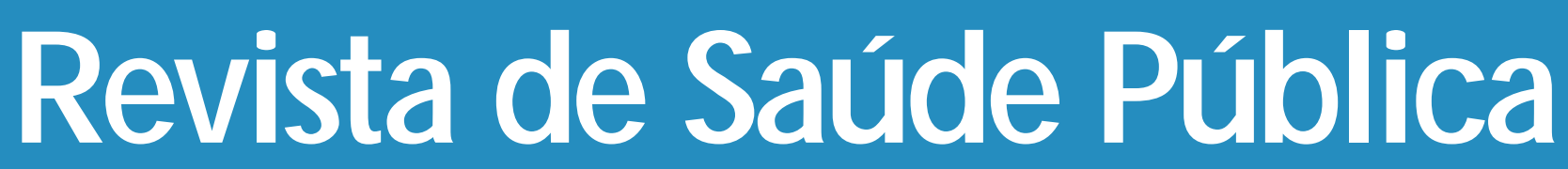

$\begin{array}{lllllll}J & 0 & \mathbf{U} & \mathbf{R} & \mathbf{N} & \mathbf{A} & \mathbf{L}\end{array}$

0 F

$\begin{array}{llllll}P & \mathbf{U} & \mathrm{B} & \mathrm{L} & \mathbf{I} & \mathbf{C}\end{array}$

H $\quad$ E $\quad A \quad L \quad T \quad H$

\title{
Indicação de vacinas e imunoglobulinas em indivíduos que apresentam comprometimento da imunidade
}

Recommendations on immunization of patients with conditions associated with general or limited immunodeficiencies 
Atualização

Current Comments

Indicação de vacinas e imunoglobulinas em indivíduos que apresentam comprometimento da imunidade

\title{
Recommendations on immunization of patients with conditions associated with general or limited immunodeficiencies
}

\author{
Lucia Ferro Bricks \\ Instituto da Criança do Hospital das Clínicas da Faculdade de Medicina da Universidade de São \\ Paulo. São Paulo, SP - Brasil
}

\begin{abstract}
Resumo
Com base na literatura, foi feita revisão sobre as recomendações para uso de vacinas e imunoglobulinas em indivíduos que apresentam comprometimento total ou parcial da imunidade, sobretudo relativa à decada de noventa. A análise de 75 referências permite chegar às principais conclusões: as vacinas contendo agentes vivos, geralmente são contra-indicadas para indivíduos que apresentam condições que determinam acentuado comprometimento da imunidade; as vacinas que contêm agentes mortos ou apenas frações antigênicas, apesar de serem menos imunogênicas e conferirem menores taxas de proteção aos imunodeprimidos, quando comparadas aos normais, são seguras e devem ser administradas a esses indivíduos. A imunização passiva é indicada nas mesmas doses para indivíduos imunodeprimidos e pessoas normais, com exceção da imunoglobulina contra o sarampo, que deve ser administrada aos imunodeprimidos no dobro das doses habituais, sempre que tiverem contato com sarampo, independentemente de sua situação vacinal anterior. Para aumentar a proteção dos imunodeprimidos contra a varicela e a influenza, recomenda-se vacinar contra essas doenças os familiares e os profissionais que atendam esses indivíduos .
\end{abstract}

Vacinas. Imunidade. Imunoglobulinas.

\begin{abstract}
A revision of the literature was made as to the recommendations given for the use of vaccines and immune globulins in persons who presented total or partial immunodeficiency, mainly related to the nineties. The analysis of 75 references led to the following principal conclusions: the vaccines containing living agents are generally inappropriate for persons who present conditions wich determine serious inmunodeficiency; the vaccines wich contain dead agents or
\end{abstract}

Correspondência para/Correspondence to: Lucia Ferro Bricks - Av. Dr. Enéas Carvalho de Aguiar, 647 - Cerqueira César - 05403-000 São Paulo, SP - Brasil. E-Mail: luciafb@icr.hcnet.usp.br 
only antigenic fractions, despite their being less immunogenic and confering lower rates of protection to severely immunocompromised persons as compared to normal persons, are safe and should be administered to them. Immunocompromised patients should receive immune globulins for the same indications and in the same doses as immunocompetent persons, with the exception of immune globulin to prevent measles, as recommended in a dosage of $0.5 \mathrm{~mL} / \mathrm{Kg}$ for immunodeficients (15mL, maximum).

Vaccines. Immunity. Immunoglobulins.

\section{INTRO DU ÇÃO}

Existem diversos tipos de comprometimento da imunidade humoral e celular; algumas condições são bastante raras, como a imunodeficiência combinada grave $^{18,19,65,70}$, outras, infelizmente, tornam-se cada vez mais freqüentes, como é o caso das imunodeficiências associadas à infecção pelo vírus da imunodeficiência humana (HIV), ao uso de corticoesteróides ou de drogas imunossupressoras para terapêutica de indivíduos portadores de neoplasias ou submetidos a transplantes 2, 7, 8, 23,51. Nos países mais pobres, a desnutrição grave ainda é um importante problema de saúde pública e a frequiência de crianças com baixo peso de nascimento é três vezes maior à encontrada em países ricos ${ }^{24}$. Nas nações industrializadas observa-se que aumenta, a cada ano, o número de idosos; apenas nos Estados Unidos, em 1990, havia mais de 30 milhões de pessoas com mais de 65 anos $^{30}$.Tanto a desnutrição (pré e pós-natal) como a idade avançada estão associadas à diminuição da imunidade celular. Além desses problemas, muitas doenças crônicas, tais como diabetes, cardiopatias, mucoviscidose, nefropatias crônicas, cirrose hepática, alcoolismo e anemia falciforme, entre outras, podem comprometer a imunidade ${ }^{1-11,13-20,22,27,29-47,54-57,61-67,70-75}$.

Em 1990, as principais causas de morte no mundo foram: doença isquêmica cardíaca (6,3 milhões); acidente cerebrovascular (4,4 milhões); infecções do trato respiratório inferior (4,3 milhões); doenças diarréicas (2,9 milhões); desordens perinatais $(2,4$ milhões); doença pulmonar obstrutiva crônica (2,2 milhões); tuberculose não associada ao $\operatorname{HIV}(2,0$ milhões); sarampo (1,1 milhão); acidentes de tráfico (1,0 milhão) e câncer de pulmão (1,0 milhão). As doenças infecciosas e parasitárias, as relacionadas à gestação e parto (incluindo os problemas perinatais) e as deficiências nutricionais foram as mais impor- tantes causas de morte nos países em desenvolvimento e, em números absolutos, foram 20 a 150 vezes mais notificadas nos países pobres do que nos países desenvolvidos. Já, os óbitos associados a neoplasias malignas, diabetes e doenças cardiovasculares, embora também mais freqüentes nos países em desenvolvimento (1,7 a 2,2 vezes), assumem, proporcionalmente, papel muito mais importante como causa de óbito nos países desenvolvidos ${ }^{50}$.

A tuberculose e o sarampo permanecem entre as principais causas de morte, apesar de existirem vacinas para sua prevenção; entretanto, com o crescente número de pessoas infectadas pelo HIV, surge a preocupação com os riscos de se administrar estas vacinas, que contêm agentes vivos, neste grupo de indivíduos. Essa preocupação se justifica, especialmente nos países em desenvolvimento, onde tanto a tuberculose como a AIDS são importantes problemas de saúde pública e o BCG é recomendado logo após o nascimento 2, 3, 5, 7-10, 17-19, 24, 26, 28, 35, 39, 50, 51, 54, 63-65. Em 1995, o número de pessoas infectadas pelo HIV foi superior a 18,5 milhões, com a maioria dos casos na África (> 11,5 milhões), sudeste asiático (3,5 milhões) e América Latina e Caribe (> 2 milhões) $)^{39}$. A infecção pelo HIV, além de estar associada a formas mais graves e ao aumento da resistência do Mycobacterium tuberculosis ${ }^{8,39}$, parece promover aumento na replicação do vírus da hepatite $\mathrm{B}$ em portadores crônicos do antígeno $\mathrm{HBs}^{23}$. Além disso, os indivíduos com AIDS que se infectam pelo vírus da hepatite B têm um período de doença aguda mais prolongado e, provavelmente, maiores chances de transmitir hepatite ${ }^{23}$.

Nos países desenvolvidos, o acesso aos serviços de saúde e o desenvolvimento de novas opções terapêuticas, permite a sobrevivência de grande número de portadores de doenças crônicas e de indivíduos que recebem tratamento imunossupressor. Apenas nos Estados Unidos, em 1992, foram realizados mais de 
2.000 transplantes de medula óssea e, aproximadamente, 9.000 transplantes renais ${ }^{75}$.

O objetivo do presente artigo é trazer aos clínicos e pediatras informações atualizadas sobre as indicações e contra-indicações das vacinas e imunoglobulinas em indivíduos que apresentam comprometimento da imunidade, visto que muitos profissionais não têm acesso a essas informações, especialmente quando se considera que os imunodeprimidos constituem grupo de risco para diversas infecções preveníveis por vacinas ainda não utilizadas de forma rotineira, como as vacinas contra pneumococos; meningococos; Haemophilus influenzae do tipo b (Hib); hepatite por vírus B, influenza e varicela.

\section{PRIN CÍPIOS GERAIS DA IMU NIZAÇÃO}

Para a indicação de qualquer vacina deve-se pesar os riscos da doença a ser prevenida e considerar os benefícios e riscos potenciais da vacinação. As vacinas contra a tuberculose, paralisia infantil, difteria, tétano, sarampo e coqueluche, que fazem parte dos calendários de vacinação da maioria dos países, são eficazes e seguras em indivíduos normais. Entretanto, nenhuma delas é totalmente eficaz ou isenta de efeitos colaterais e, além disso, pouco se conhece sobre sua imunogenicidade, segurança e duração da proteção quando administradas em imunodeprimidos 2-10, 24, 26-33, 37-45, 53, 54, 62-64, 69,73.

Assim como existem diversas causas de comprometimento da imunidade, o grau desse comprometimento pode variar de acordo com a evolução da doença e/ou tipo de tratamento ao qual o indivíduo está sendo submetido e, cabe ao médico avaliar, em cada caso, as indicações e contra-indicações de cada vacina. Em geral, as vacinas são contra-indicadas em duas situações $2,3,5,8,9,24$ :

- antecedente de reação de caráter anafilático à dose anterior da vacina;

- doença moderada ou grave, com ou sem febre.

$\mathrm{O}$ indivíduo que apresenta comprometimento da imunidade tem, em geral, como causa básica doença moderada ou grave, estando, portanto, contraindicada sua vacinação. Quando se aplicam vacinas contendo agentes vivos em imunodeprimidos existe a possibilidade de disseminação da bactéria ou vírus que, mesmo atenuados, podem causar doença e até a morte nesses indivíduos. As vacinas que não contêm agentes vivos não causam maiores danos às pessoas com depressão da imunidade e, por esse motivo, são indicadas para os imunodeficientes no mesmo esque- ma e doses recomendados para pessoas normais. Entretanto, pela própria imunodepressão, a imunogenicidade e a produção de anticorpos poderão estar prejudicadas e, sempre que possível, a vacinação deve ser adiada 2-9, 15-17, 20, 24, 30, 37 .

\section{PRINCIPAIS CONDIÇÕES CLÍNICAS ASSO CIADAS AO CO MPRO METIMENTO DA IMUNIDADE}

\section{Desnutrição}

Embora crianças com desnutrição primária grave possam apresentar um comprometimento da imunidade celular, observa-se que a imunidade humoral não é comprometida e as vacinas do calendário básico são consideradas seguras e imunogênicas nos desnutridos. Além disso, deve-se ressaltar que doenças como sarampo, coqueluche, tuberculose são mais graves no desnutrido do que nos normais. Portanto, considerando-se os riscos e benefícios da vacinação, a desnutrição é considerada indicação e não contraindicação para as vacinas ${ }^{3,9,24}$.

\section{Recém-nascidos de Baixo Peso}

As crianças nascidas de baixo peso são vulneráveis a diversas infecções por apresentarem deficiência na imunidade celular. Os prematuros têm menores taxas de imunoglobulina da classe $\operatorname{IgG}$, que são adquiridas da mãe, por via transplacentária. Apesar desses problemas, diversos estudos têm demonstrado que as vacinas contra difteria, tétano, coqueluche e paralisia infantil induzem resposta sorológica semelhante à obtida em crianças nascidas a termo e que, portanto, devem ser administradas aos recémnascidos de baixo peso e aos prematuros nas mesmas doses, idade cronológica e esquema recomendados para crianças nascidas com peso normal ${ }^{1,3,5,9}$, 11, 12, 24, 40, 43, 46, 59, 60, 66, 73. Entretanto, a incidência de complicações locais pós-vacina BCG é maior nas crianças vacinadas antes de atingirem o peso de $2.000 \mathrm{~g}$, sendo recomendável que esta vacina seja administrada após a criança ter atingido este peso. ${ }^{9,24}$ Outra vacina que deve ser administrada após a criança ter atingido o peso de $2.000 \mathrm{~g}$ é a vacina contra hepatite por vírus $\mathrm{B}$, pois sua imunogenicidade é menor em crianças de baixo peso ao nascer ${ }^{3,9,46,60}$. Recentemente, Kim e col. ${ }^{40}$ (1997) estudaram a imunogenicidade da vacina contra hepatite B em 102 prematuros, com idade gestacional entre 23 e 36 se- 
manas e obtiveram $90 \%$ de resposta após 3 doses da vacina (títulos de antiHBs $\geq 10 \mathrm{mUI} / \mathrm{ml}$ ), porém, os títulos de anticorpos foram muito inferiores aos obtidos em crianças nascidas a termo (GTM 200 mIU/ $\mathrm{ml}$ ). Apesar da menor imunogenicidade da vacina contra hepatite B em crianças de baixo peso ao nascer, recomenda-se que esta vacina seja administrada logo após o nascimento, independentemente do peso da criança, sempre que a mãe for positiva para o antígeno HBs. Nesta situação a criança também deverá receber a imunoglobulina específica (HBIG), por via intramuscular, na dose de $0,5 \mathrm{ml}^{3,5,9,24,40,60}$.

Embora as crianças nascidas antes de 30 semanas de gestação apresentem menor resposta às vacinas contra o $H$. influenzae tipo b (Hib), a imunização deve ser feita de acordo com a idade cronológica, pois o risco de doença invasiva por Hib é inversamente proporcional à idade ${ }^{59}$, e muitos prematuros podem beneficiar-se com a vacinação contra o Hib ${ }^{43,66,73}$.

\section{U so de Corticoesteróides}

O uso de corticoesteróides é muito freqüiente em diversas situações clínicas: tratamento de asma moderada ou grave, síndrome nefrótica, colagenoses e neoplasias. Sabe-se que esses medicamentos podem prejudicar a produção de anticorpos, sempre que utilizados em dose superior à dose fisiológica, porém, ainda não se conhecem a dose exata e o tempo de uso de corticoesteróides necessários para suprimir a resposta imunológica. A maioria dos autores considera que a imunodepressão não ocorre nas seguintes situações:

- uso de corticoesteróides por período inferior a 2 semanas;

- dose baixa ou moderada de corticoesteróides (até $2 \mathrm{mg} / \mathrm{kg} / \mathrm{dia}$ ou $20 \mathrm{mg} /$ dia de prednisona ou equivalente, na criança);

- uso de corticoesteróides por via tópica, inalatória, intraarticular, ou em tendões.

Nas situações acima não existe contra-indicação para a vacinação. Quando o uso de corticoesteróides for prolongado (superior a 2 semanas) ou as doses forem elevadas (> $2 \mathrm{mg} / \mathrm{kg} / \mathrm{dia}$ ou $20 \mathrm{mg} / \mathrm{dia}$ de prednisona ou equivalente), estão formalmente contra-indicadas as vacinas contendo agentes vivos (BCG; Sabin; sarampo; caxumba; rubéola; varicela; febre amarela; raiva e febre tifóide) $)^{2-5,9,30,44,48,49,55,67}$.

Recomenda-se aguardar pelo menos 3 meses após a suspensão do uso de corticoesteróides antes de se administrar qualquer vacina contendo agentes vivos ${ }^{2-9,24}$.

\section{Imunodepressão Grave não Associada à Infecção pelo HIV}

Neste grupo estão incluídos os indivíduos com imunodepressão congênita; leucemia; linfoma; neoplasias malignas generalizadas e aqueles que recebem tratamento com agentes alquilantes, antimetabólitos, radiação ou corticoesteróides em doses elevadas. As vacinas contendo agentes vivos são formalmente contra-indicadas para esse grupo de indivíduos, porém, infelizmente, em algumas situações a imunodepressão só será reconhecida após a criança ter recebido uma ou mais vacinas do calendário básico 2, 3, 5, 7-9, 18, 19, 26, 35, 70, 72 .

A principal condição associada à disseminação do BCG é a imunodeficiência combinada grave e, nesta situação, a evolução é, geralmente, fatal ${ }^{65}$. Casanova e col. ${ }^{18}$ (1995), em revisão da literatura mundial, encontraram 121 crianças que tiveram infecção disseminada pelo BCG. Em 60 crianças (50\%) não foi identificada a causa desta complicação; no restante, a causa mais freqüente foi a imunodeficiência combinada grave, num total de 45 casos $(37 \%)$. As outras crianças apresentavam: doença granulomatosa crônica, 11 casos (9\%); AIDS, 4 casos (3\%) e síndrome de Di Giorge completa, um caso (1\%).

Na França, onde o BCG é exigido por lei para admissão à escola e a maioria das crianças recebe a vacina no primeiro ano de vida, Casanova e col. ${ }^{19}$ (1996) encontraram 16 casos idiopáticos de disseminação do BCG, em um levantamento nacional sobre todos os casos ocorridos entre 1974 e 1994. Apesar de não se ter identificado a causa da disseminação do Mycobacterium bovis, 1/3 das crianças francesas com disseminação do BCG tinham história familiar de consangüinidade e o mesmo foi encontrado na revisão da literatura mundial; entre os 60 casos de disseminação do BCG considerados idiopáticos foram encontrados 4 pares de primos de primeiro grau e um par de irmãos, o que sugere algum tipo de imunodefiência familiar ainda desconhecida, provavelmente de caráter autossômico recessivo ${ }^{18,19,35}$.

A vacina Sabin não deve ser administrada aos indivíduos com imunodepressão grave, pois existem relatos de disseminação do poliovírus atenuado, que pode causar paralisia até 6 meses após a administração da vacina oral em imunodeprimidos ${ }^{28}$. Indivíduos normais podem excretar o poliovírus atenuado em suas fezes até 4 a 6 semanas após terem recebido a vacina oral contra a poliomielite. Portanto, recomenda-se que os imunodeprimidos e seus contatos íntimos sejam vacinados com a vacina inativada de 
potência aumentada contra a poliomielite (VIP). Se um contato domiciliar de pessoa portadora de imunodeficiência for inadvertidamente vacinado com a vacina oral, deve-se evitar o contato físico com o imunodeficiente por, pelo menos, 4 a 6 semanas (período máximo de excreção viral). No Brasil e em países onde são realizadas as campanhas anuais de vacinação contra a poliomielite é praticamente impossível evitar o contato com indivíduos recentemente vacinados com a vacina oral. Assim sendo, recomenda-se redobrar os cuidados com as medidas de higiene, para evitar que os imunodeprimidos entrem em contato com as fezes e a saliva dos vacinados $2,3,9,17,28$.

Embora o sarampo cause doença grave e, geralmente, fatal em pessoas com imunodepressão grave, a vacina contra o sarampo é contra indicada para esse grupo de indivíduos, tendo em vista que contém vírus vivos e que já foram confirmados, apenas nos Estados Unidos, pelo menos 5 óbitos pela disseminação do vírus atenuado do sarampo em pessoas com imunodepressão grave ${ }^{5}$. Nesta situação, recomenda-se a imunização passiva para prevenir o sarampo. Indivíduos com imunodepressão grave, que tiverem contato com casos de sarampo, devem receber imunoglobulina, independentemente de terem sido previamente vacinados. A dose de imunoglobulina é o dobro da recomendada para pessoas normais $(50 \mathrm{mg} / \mathrm{kg} / \mathrm{dose} \text {, no máximo } 20 \mathrm{ml})^{\mathbf{2 , 3 , 5 , 9}}$.

No caso de indivíduos submetidos a transplante de órgãos, existem poucos estudos sobre a eficácia das vacinas; entretanto, recomenda-se que indivíduos submetidos a transplante de medula óssea sejam revacinados com as vacinas inativadas, um ano após o transplante, a menos que seus anticorpos estejam acima dos títulos considerados protetores. São preconizadas 3 doses dos toxóides tetânico e diftérico (intervalo de 2 meses); vacinação contra hepatite B (3 doses - 0, 1, 6 meses); vacinação anual contra influenza; vacina contra pneumocócos e contra $H$. influenzae do tipo B.

Recomenda-se dosar os anticorpos contra hepatite $\mathrm{B}$, após completar a série de 3 doses e, se não houver resposta, revacinar (máximo de mais 3 doses). As vacinas contendo agentes vivos (sarampo, caxumba e rubéola) só devem ser administradas 2 anos após o transplante de medula óssea e a Academia Americana de Pediatria (AAP) recomenda que a vacina tríplice viral seja dada em esquema de 2 doses, com intervalo de 4 semanas. A vacina contra varicela não deve ser administrada a indivíduos submetidos a transplante de medula óssea, pois não existem dados sobre sua segurança. ${ }^{13}$
Sempre que possível, recomenda-se dosar os títulos de anticorpos contra hepatite B, sarampo, rubéola, caxumba, varicela, pois a resposta sorológica pode não ser adequada, mesmo após revacinação. Quando os indivíduos imunodeprimidos são expostos a doenças infecciosas, o uso de imunização passiva deve ser recomendado com base em evidências sorológicas de suscetibilidade. ${ }^{13}$

\section{Imunodeficiência Associada à Infecção pelo HIV}

A infecção pelo HIV pode produzir um amplo espectro de graus de comprometimento da imunidade, que varia desde os graus leves que não são acompanhados de sintoma, até o comprometimento da imunidade humoral e celular. Indivíduos assintomáticos apresentam, inicialmente, um déficit da imunidade humoral, com diminuição da produção de anticorpos; conforme a doença progride, além do comprometimento da imunidade humoral, existe uma queda no número de linfócitos CD4+, com diminuição também da imunidade celular ${ }^{\mathbf{8 , 1 4 , 3 8 , 6 2 , 6 3 , 6 9}}$. O comprometimento da imunidade predispõe esses indivíduos a um maior número de infecções graves que podem ser prevenidas por imunização ativa, passiva ou pelo uso profilático de antibióticos ${ }^{2-10,14,15,20,30}$.

Das vacinas do calendário básico, a Organização Mundial de Saúde (OMS) contra-indica apenas a vacina BCG para pessoas que já apresentam os sintomas da AIDS, enquanto a AAP e o Órgão Acessor em Práticas de Imunização dos Estados Unidos (ACIP) contra-indicam a vacina BCG e a vacina oral contra a poliomielite para todos os infectados pelo HIV (sintomáticos e assintomáticos) ${ }^{\mathbf{9}, 24}$.

Nos Estados Unidos a tuberculose não é um problema importante de saúde pública e a vacina BCG não faz parte do calendário básico de imunizações daquele país. Entretanto, em locais onde a tuberculose é de alta endemicidade, como é o caso do Brasil, a OMS recomenda que a vacina BCG seja administrada precocemente às crianças, de preferência no primeiro mês de vida, para evitar as formas graves da doença (meningite tuberculosa e tuberculose miliar) que são mais comuns em lactentes. Infelizmente, tanto a tuberculose como a infecção pelo HIV são mais comuns em países pobres, onde é inviável fazer a triagem sorológica para o HIV, em todas as gestantes. Além da impossibilidade de fazer a triagem sorológica para o HIV em todos os recém-nascidos, é muito difícil confirmar ou afastar a infecção pelo HIV quando a mãe é soropositiva, visto que 100\% dos recém-nascidos de mães positivas para o 
HIV nascem com anticorpos para o vírus; porém, a taxa de transmissão materno-fetal da infecção ocorre em apenas $12 \%$ a $40 \%$ das crianças de mães soropositivas ${ }^{7}$. A dificuldade em estabelecer o diagnóstico de infecção pelo HIV no recém-nascido, a alta incidência de tuberculose em países em desenvolvimento e o pequeno número de casos descritos de formas disseminadas de infecção pelo BCG em crianças infectadas pelo HIV, associadas ao fato de as formas graves de tuberculose ocorrerem com maior frequiência em lactentes, são os principais argumentos a favor da vacinação com BCG em crianças HIV-positivas assintomáticas, conforme recomendação da OMS 2, 3, 5, 7-9. Ainda são poucos os estudos sobre a eficácia, imunogenicidade e segurança do BCG em crianças infectadas pelo HIV e existem, pelo menos, 11 casos de disseminação do BCG em crianças HIV-positivas vacinadas contra a tuberculose antes do terceiro mês de vida. Essas crianças apresentaram os primeiros sintomas de disseminação do $M$. bovis entre 3 meses e 3 anos após a vacinação $0^{26,35,51,63-65}$. Em São Paulo, entre 1984 e 1994, foram encontrados dois casos de disseminação do BCG em crianças infectadas pelo HIV e matriculadas em um hospital infantil de São Paulo. Essas crianças se recuperaram da infecção pelo BCG com tratamento específico, apesar de a bactéria ter sido isolada e cultivada na medula óssea ${ }^{64}$. Entretanto, já foram confirmados pelo menos 3 óbitos por disseminação do BCG em crianças que haviam recebido essa vacina antes do início dos sintomas da AIDS 18,26,64. Um dos óbitos ocorreu nos Estados Unidos, mas a criança havia nascido e sido vacinada no Brasil ${ }^{26}$. Estes dados demonstram que pode ocorrer a disseminação do $M$. Bovis-BCG em crianças infectadas pelo HIV e vacinadas antes de desenvolverem os sintomas da doença; entretanto, como o risco de disseminação do M. bovis é baixo e a vacina BCG é considerada como importante medida de controle para as formas graves de tuberculose, a OMS mantém a recomendação para que todas as crianças nascidas em locais de alta endemicidade, para tuberculose, recebam o BCG mesmo quando infectadas pelo HIV, desde que não apresentem sintomas da doença $2,8,9,64$.

A vacina BCG não é recomendada para adultos infectados pelo HIV, pois existem poucas evidências de que a vacinação possa beneficiar esses indivíduos ${ }^{8}$. Apesar de serem raros os casos de disseminação do BCG em adultos, já ocorreram pelo menos dois óbitos em adultos vacinados antes do início dos sintomas da doença. A disseminação ocorreu entre 5 meses $^{64} \mathrm{e}$ $30 \operatorname{anos}^{72}$ após a vacinação e os óbitos foram por pneumonia e meningite, tendo ocorrido, respectivamente, 4 e 12 anos após a vacinação $0^{64,72}$.

Quanto à vacina oral contra a poliomielite, apesar dos riscos potenciais de disseminação dos vírus atenuados, até o presente não foi comprovado nenhum caso de disseminação do vírus vacinal em indivíduos infectados pelo HIV e, por esse motivo, a OMS recomenda que esses indivíduos sejam vacinados com a vacina Sabin. Por precaução, o ACIP recomenda que todos indivíduos HIV-positivos, sintomáticos ou doentes, bem como seus familiares e contatos íntimos (domiciliares, de creches, escolas e enfermarias) sejam vacinados com a vacina inativada que, além de ser mais imunogênica é isenta do risco de disseminação $0^{2,8,9,24}$.

A vacina contra o sarampo é recomendada tanto pela OMS como pelo ACIP para indivíduos infectados pelo HIV (assintomáticos e doentes). Embora a soroconversão à vacina do sarampo esteja diminuída em infectados pelo HIV, a vacina é aparentemente segura. Todavia, em 1996, foi confirmado um óbito por pneumonia causada pelo vírus atenuado do sarampo. Por esse motivo, o ACIP recomenda que nos indivíduos HIV-positivos seja feita, previamente à administração da vacina contra o sarampo, a contagem de linfócitos $\mathrm{CD} 4++^{5,8}$. Segundo o ACIP, a vacina estaria contra-indicada quando a contagem de linfócitos CD4+ for inferior a:

- $750 / \mathrm{mm}^{3}$, em menores de um ano;

- $500 / \mathrm{mm}^{3}$, em crianças com idade entre um e 5 anos;

-200/mm³, em indivíduos com mais de 6 anos de idade.

Outro critério é o percentual de linfócitos T-CD4+ em relação à contagem total de linfócitos, considerando-se que existe imunodepressão grave quando o percentual de $\mathrm{CD} 4+$ for inferior a $15 \%$ em menores de 13 anos, ou inferior a 14\%, em indivíduos com 13 anos ou mais ${ }^{5}$.

Ainda se desconhece a eficácia e a duração da proteção conferidas pela vacina contra o sarampo em indivíduos infectados pelo HIV. Recentemente, no Zâmbia ${ }^{54}$, foram levantadas dúvidas sobre a segurança dessa vacina nesse grupo de indivíduos, visto que a vacina não reduziu a mortalidade por sarampo em meninos infectados pelo HIV e, em meninas infectadas pelo HIV, observou-se um maior risco relativo de morte por sarampo no grupo vacinado, quando comparado ao grupo não vacinado.

Como faltam estudos nesta área, considera-se que, sempre que possível, dever-se-ia avaliar a imunidade das crianças infectadas pelo HIV antes da administração das vacinas contendo agentes vivos, espe- 
cialmente, BCG e sarampo.

As vacinas contra difteria, tétano e coqueluche (DPT, DT, dT, T) e as vacinas polissacarídicas contra pneumococos, Hib e meningococos são inativadas e, portanto, não apresentam riscos de disseminação em imunodeprimidos. São recomendadas no mesmo esquema e doses indicadas para indivíduos normais. Deve-se ressaltar, todavia, que sua imunogenicidade é menor em indivíduos infectados pelo HIV e ainda faltam estudos sobre a necessidade de reforços $2,3,5,7,10,14,69$.

Recentemente, verificou-se que a administração de algumas vacinas inativadas (DPT e influenza) a indivíduos infectados pelo HIV tipo 1 promovia um aumento na expressão dos vírus da AIDS; entretanto, esse aumento é transitório e ainda se desconhece seu significado clínico ${ }^{8,53,68}$.

\section{O utras Condições Associadas à Imunodepressão}

Existem diversas outras condições associadas à imunodepressão: indivíduos idosos apresentam uma queda da imunidade celular e são sujeitos a um maior risco de infecções por Streptococcus pneumoniae (pneumococos), influenza e varicela; infecções graves por pneumococos e influenza também ocorrem em portadores de doenças cárdio-respiratórias crônicas (incluindo asma), diabéticos, portadores de nefropatias crônicas, hemodialisados, cirróticos e alcoólatras. Indivíduos com asplenia de causa anatômica ou funcional têm maior risco de doença invasiva por pneumococos, meningococos e $H$. influenzae tipo b e os diabéticos apresentam maior

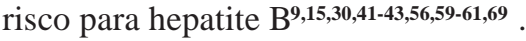

A seguir serão apresentados alguns estudos sobre a eficácia e imunogenicidade das vacinas contra hepatite B; pneumococos, Hib e influenza em imunodeprimidos. O leitor interessado em uma discussão mais detalhada sobre cada uma dessas vacinas deve reportar-se às referências citadas no texto.

\section{VACINA CONTRA HEPATITE B}

A hepatite B é um problema importante de saúde em todo o mundo, tendo em vista que é altamente contagiosa, mesmo quando o indivíduo não apresenta qualquer sintoma da doença. Mesmo quando a infecção pelo vírus da hepatite B cursa de forma assintomática, a doença pode cronificar, causando complicações tardias. A cirrose e o câncer hepático, que são as principais complicações da hepatite B, a cada ano, causam mais de um milhão de mortes no mundo. A vacina contra hepatite por vírus B é altamente imunogênica, segura e eficaz, e já foi demonstrado que, além de proteger contra a doença, é capaz de reduzir a incidência de complicações tardias, como o câncer hepático ${ }^{\mathbf{2 1 , 4 7}}$. Desde 1991, a vacina contra hepatite por vírus B é recomendada pela OMS para vacinação universal, visto que não se consegue identificar a fonte de contágio em 30 a $40 \%$ dos portado-

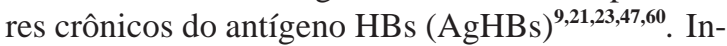
felizmente, a vacina contra hepatite $B$ ainda não foi incorporada ao calendário de vacinação no Brasil, onde continua sendo recomendada apenas para os grupos de risco, entre os quais se incluem:

- recém-nascidos de mãe positiva para o AgHBs (vacina + imunoglobulina específica);

Tabela 1 - D oses recomendadas das vacinas contra hepatite por vírus B.

\begin{tabular}{|c|c|c|c|c|}
\hline \multirow{2}{*}{$\begin{array}{l}\text { Categorização de pacientes } \\
\text { Crianças < } 11 \text { anos, quando a mãe } \\
\text { for soronegativa para o antígeno } \mathrm{HBs}\end{array}$} & \multicolumn{2}{|c|}{$\begin{array}{l}\text { Recombivax } \\
\text { (Merck \& Co) } \\
\text { dose: } \mu \mathrm{g}(\mathrm{ml})\end{array}$} & \multicolumn{2}{|c|}{$\begin{array}{c}\text { Engerix-B } \\
\text { (SmithKline Beecham) } \\
\text { dose: } \mu \mathrm{g}(\mathrm{ml})\end{array}$} \\
\hline & 2,5 & $(0,5)^{*}$ & 10 & $(0,5)$ \\
\hline $\begin{array}{l}\text { Recém-nascidos de mães } \\
\text { soropositivas para o antígeno HBs } \\
\text { (administrar também HBIG, } 0,5 \mathrm{~mL} \text {, via IM ) }\end{array}$ & 5 & $\begin{array}{l}(1,0)^{*} \\
(0,5)^{* *}\end{array}$ & 10 & $(0,5)$ \\
\hline $\begin{array}{l}\text { Crianças e adolescentes } \\
\text { com idade entre } 11 \text { e } 19 \text { anos }\end{array}$ & 5 & $(0,5)^{* *}$ & 10 & $(0,5)$ \\
\hline Adultos $\geq 20$ anos & 10 & $(1,0)^{* *}$ & 20 & $(1,0)$ \\
\hline $\begin{array}{l}\text { Imunodeprimidos e } \\
\text { pacientes de diálise }\end{array}$ & 40 & $(1,0) * * *$ & 40 & $(2,0)^{* * * *}$ \\
\hline
\end{tabular}

Fonte: Academia Americana de Pediatria ${ }^{9}, 1997$

* formulação pediátrica

** formulação para adultos

*** formulação especial para pacientes submetidos à diálise

**** duas doses de 1,0 ml devem ser administradas, em esquema de 4 doses, nos meses $0,1,2$, e 6 a 12 meses após a terceira dose. 
- indivíduos que necessitam receber sangue ou derivados (portadores de anemias hemolíticas, hemofilia, plaquetopenia);

- indivíduos com risco profissional: pessoas que têm contato com sangue (médicos, dentistas, pessoal de laboratório) ou que trabalham em instituições para deficientes mentais;

- profilaxia pós-exposição, como picada com agulha contaminada ou contato sexual com portador do AgHBs (vacina + imunoglobulina específica);

- residentes em zonas de alto endemicidade;

- usuários de drogas por via injetável;

- homossexuais, bissexuais e promíscuos;

- indivíduos submetidos à hemodiálise;

- imunodeprimidos $\mathbf{9 , 6 0}$.

Os portadores de doenças que comprometem a imunidade e os indivíduos que fazem hemodiálise devem receber um esquema de 4 doses duplas da vacina contra hepatite $\mathrm{B}$, pois, nestes indivíduos, observa-se menor resposta ao esquema de vacinação com 3 doses (Tabela 1).

El-Reshaid e col. ${ }^{27}$ (1994), em estudo multicêntrico, encontraram $79 \%$ de soroconversão entre indivíduos negativos para o antígeno $\mathrm{HBs}$ que foram vacinados com 4 doses duplas da vacina Engerix $\mathrm{B}^{\mathrm{R}}$ , no esquema de $40 \mu \mathrm{g}$ nos meses $0,1,2$ e 6; porém, no grupo vacinado com 3 doses de duplas $(40 \mu \mathrm{g}$ nos meses 0,1 e 6 ) a resposta foi obtida em somente $55 \%$. Todos os controles saudáveis soroconverteram após 3 doses de $20 \mu \mathrm{g}$. Após dois anos, 30\% dos indivíduos vacinados com esquema de 3 doses duplas da vacina haviam negativado os anticorpos, enquanto no grupo vacinado com 4 doses, apenas $6 \%$ tornaram-se soronegativos. A pior resposta foi observada entre indivíduos mais velhos (maiores de 65 anos) e diabéticos.

Fabrizi e col. ${ }^{29}$ (1996) demonstraram que a vacina recombinante (Engerix $\left.\mathrm{B}^{\mathrm{R}}\right)$, administrada em esquema de 3 doses de $40 \mu \mathrm{g}$ em adultos submetidos à hemodiálise, produziu soroconversão em apenas $67 \%$ dos vacinados. A pior resposta foi observada em diabéticos, desnutridos, idosos e em indivíduos com positividade para o antígeno $\mathrm{HBc}$.

Fiçioglu e col. ${ }^{31}$ (1995) verificaram que uma vacina $\left(\right.$ Genhevac $\mathrm{B}^{\mathrm{R}}$ ) contra hepatite $\mathrm{B}$, administrada no esquema de 3 doses ( 0,1 e 2 meses) a crianças diabéticas com idade entre 2 e 10 anos, foi pouco imunogênica, promovendo apenas $46 \%$ de soroconversão. Todas as crianças responderam à quarta dose e os autores recomendam que as crianças diabéticas, assim como os imunodeprimidos e submetidos à hemodiálise recebam 4 doses da vacina contra hepatite $\mathrm{B}$.
Hovi e col. ${ }^{37}$ (1995) demonstraram que em crianças em uso de quimioterapia para tratamento de câncer a vacina plasmática contra hepatite $\mathrm{B}$, em esquema de 3 doses duplas ( $20 \mu \mathrm{g} /$ dose ) foi pouco eficaz. Em 36 crianças em quimioterapia a resposta à vacina foi obtida em apenas 67\% (GTM 1076 mUI/ $\mathrm{ml}$ ), enquanto nas crianças que não estavam recebendo quimioterapia a resposta foi semelhante à obtida no grupo-controle (97\% soroconversão, com $\mathrm{GTM}=18.883 \mathrm{mUI} / \mathrm{ml})$.

As vias de transmissão do HIV e do vírus da hepatite B são as mesmas e os indivíduos HIV-positivos têm $20 \%$ a $30 \%$ de chance de já terem sido contaminados pelo vírus da hepatite $\mathrm{B}$, quando é feito o diagnóstico de AIDS, em comparação com $6 \%$ a $10 \%$ dos controles. A vacina contra hepatite B é menos imunogênica em infectados pelo HIV (50\% a 70\% de soroconversão) e, além disso, esses indivíduos negativam mais rapidamente os anticorpos. Portanto, recomenda-se verificar a soroconversão após completar o esquema de vacinação em imunodeprimidos e quando o título de anticorpos for inferior a $10 \mathrm{mUI} /$ ml deve-se administrar uma ou mais doses da vacina ${ }^{8,9}$.

\section{VACINA ANTIPNEUMOCÓCICA}

A vacina contra pneumococos é indicada para indivíduos com mais de 2 anos de idade, nas seguintes situações:

- idosos ( > 65 anos);

- imunodeprimidos (incluindo HIV-positivos sintomáticos e assintomáticos);

- portadores de asplenia anatômica ou funcional (incluindo anemia falciforme);

- portadores de doenças crônicas (nefropatias, doenças cárdio-respiratórias, diabetes, alcoolismo, cirrose)

- indivíduos com fístula liquórica.

Existem mais de 80 sorotipos de pneumococos que podem causar doença grave e a vacina polissacarídica atualmente em uso só contêm 23 sorotipos. Embora os sorotipos contidos na vacina sejam os principais responsáveis por doenças invasivas, mesmo em indivíduos normais, observase uma ampla variação na resposta à vacina 23-valente; além disso, não existe resposta uniforme a todos os sorotipos e a proteção conferida pela vacina é variável $^{34}$. Estima-se que a eficácia conferida pela vacina antipneumocócica em adultos saudáveis seja de $70 \%$ a $90 \%$, porém, nos imunodeprimidos essa proteção é bem menor. Quanto maior o grau de comprometimento da resposta imunológica, maior o ris- 
co de doença invasiva grave por pneumococos e menor a resposta à vacina. A eficácia da vacina diminui com a idade e o tempo após a vacinação. A melhor resposta à vacina antipneumocócica é observada em indivíduos esplenectomizados quando a vacina é administrada duas semanas antes da esplenectomia. Em crianças com anemia falciforme, recomenda-se fazer a vacina e a profilaxia com penicilina, conseguindo-se uma redução em torno de $80 \%$ no risco de doença grave ${ }^{9,15,24,30}$.

As crianças com síndrome nefrótica são de maior risco para infecções graves por Streptococcus pneumoniae, porém, para tratar a síndrome nefrótica, recomenda-se o uso prolongado de corticoesteróides, e esses medicamentos podem comprometer a resposta à vacina. Portanto, sempre que possível, recomenda-se vacinar as crianças com síndrome nefrótica antes do início da corticoterapia ${ }^{15,30}$. Spika e col. ${ }^{67}$ (1982) demonstraram que, em nefróticos, as concentrações de anticorpos contra o pneumococos estão diminuídas antes e após a vacinação, porém, após a suspensão do corticóide obtém-se boa resposta à vacina. Já foi demonstrado que entre as crianças com síndrome nefrótica córtico-sensível a resposta à vacina é superior à obtida nas crianças com doença córtico-dependente ${ }^{48,67}$.

Lee e col. ${ }^{48}$ (1995) estudaram a imunogenicidade da vacina 23-valente contra o pneumococos em 119 crianças e adolescentes (2 a 18 anos): 21 saudáveis, 26 esplenectomizados, 48 com síndrome nefrótica e 24 asmáticos. A vacina demonstrou ser bastante segura em todos os grupos, produzindo febre $\left(>38,2^{\circ} \mathrm{C}\right)$ em menos de $2 \%$ dos vacinados e foi capaz de induzir resposta imunológica, com produção de pelo menos duas vezes o título de anticorpos em comparação com os níveis pré-vacinação, em todos os grupos, independentemente de estarem ou não recebendo corticoterapia. As crianças com síndrome nefrótica apresentaram menores títulos de anticorpos em relação aos outros grupos.

Em indivíduos infectados pelo HIV, o risco de doença invasiva por pneumococos é 100 vezes superior aos controles normais e a letalidade, duas vezes maior ${ }^{6}$. Neste grupo, observa-se que o título de anticorpos contra pneumococos antes da vacinação é 3 a 5 vezes inferior ao encontrado nos grupos controles ${ }^{8}$. Portanto, a vacina tem indicação formal para esses indivíduos. Como já foi demonstrado que, conforme a doença progride, diminui a resposta à vacina, recomenda-se vacinar o mais precocemente possível os indivíduos HIV-positivos, enquanto não existe grande redução no número de linfócitos T CD4+2,3,6,8,10,15,24,30,61.
Atualmente, estão em fase de teste as vacinas conjugadas contra o pneumococo. Aparentemente, as novas vacinas conjugadas são mais imunogênicas do que a vacina polissacarídica, porém, ainda não são comercializadas ${ }^{15,30,41,42,48}$.

\section{VACINAS CONTRA HAEMOPHILUS INFLUENZAE DO TIPO B}

As vacinas conjugadas contra Hib já fazem parte do calendário vacinal de diversos países e têm excelente eficácia e imunogenicidade. $\mathrm{O}$ esquema de vacinação depende do tipo de vacina utilizada e da idade da criança (Tabela 2). Além de serem recomendadas para todas as crianças menores de 5 anos, são indicadas para os esplenectomizados e para os imunodeprimidos, incluindo os portadores assintomáticos do vírus da AIDS, visto que estes indivíduos apresentam maior risco de infecção disseminada pelo $\mathrm{Hib}^{\mathbf{2 , 3 9 , 5 9}}$. Alguns autores preconizam o uso de uma dose de reforço da vacina contra o Hib, um ano após a primeira dose, para imunodeprimidos vacinados após um ano de idade ${ }^{9}$.

Apenas 4\% dos indivíduos HIV-positivos apresentam títulos de anticorpos protetores contra o Hib, em comparação com $40 \%$ dos indivíduos normais. Apesar de o risco de pneumonia por Hib e de doença invasiva por esse agente serem bastante elevados em imunodeprimidos, a resposta à vacina em infectados

Tabela 2- Esquema de vacinação contra o Haemophilus influenzae tipo b.

\begin{tabular}{|c|c|c|c|}
\hline Vacinas & $\begin{array}{c}\text { Idade } \\
\text { de início } \\
\text { 1â dose } \\
\text { (meses) }\end{array}$ & $\begin{array}{l}\text { Esquema } \\
\text { básico }\end{array}$ & Reforço \\
\hline PRP - T & $02-06$ & 3 doses $*$ & $\overline{12-15 \text { meses }}$ \\
\hline$\left(\text { Act }-\mathrm{HIB}^{\circledR}\right)^{1} /$ & $07-11$ & 2 doses * & $12-18$ meses \\
\hline $\begin{array}{l}\mathrm{HbOC} \\
\left(\mathrm{HibTITER}^{\circledR}\right)^{2}\end{array}$ & $\begin{array}{r}12-14 \\
\geq 15\end{array}$ & $\begin{array}{l}1 \text { dose } \\
\text { dose única* }\end{array}$ & 2 meses após \\
\hline $\begin{array}{l}\text { PRP - OMP } \\
\left(\text { Pedvax HIB }{ }^{\circledR}\right)^{3}\end{array}$ & $\begin{array}{l}02-06 \\
07-11 \\
12-14 \\
\geq 15\end{array}$ & $\begin{array}{l}2 \text { doses } * \\
2 \text { doses } * \\
1 \text { dose } \\
\text { dose única** }\end{array}$ & $\begin{array}{l}12 \text { meses } \\
15 \text { meses } \\
15 \text { meses }\end{array}$ \\
\hline $\begin{array}{l}\text { PRP-D } 4 \\
\left.\text { (ProHIBiT }{ }^{\circledR}\right)\end{array}$ & $\geq 15$ & dose única** & - \\
\hline
\end{tabular}

* 0 intervalo mínimo entre as doses deve ser de 2 meses.

${ }^{*}$ Alguns autores recomedam uma dose de reforço para os imunodeprimidos, 12 meses após a primeira dose.

${ }_{1}^{1}$ PRP-T ( nome comercial ActHIB ${ }^{\circledR}$ ) é fabricada pelo laboratório Pasteur M érieux e pode ser administrada de forma combinada (mesma seringa e agulha) com a vacina DPT fabricada pelo laboratório Connaught.

${ }^{2} \mathrm{HbOC}$ ( nome comercial HibTITER ${ }^{2}$ ) é fabricada pelo laboratório $W$ yethLederle e existe também a forma combinada com a vacina DPT

(TETRAM UNE ${ }^{\circledR}$ )

${ }^{3}$ PRP-O MP ( nome comercial PedvaxHIB ${ }^{\circledR}$ ) é fabricada pelo laboratório Merck

${ }^{4}$ PRP-D (nome comercial ProHIBiT ${ }^{\circledR}$ é fabricada pelo laboratório Connaught. 
Tabela 3 - Esquema de vacinação contra influenza.

\begin{tabular}{|c|c|c|c|}
\hline Idade & $\begin{array}{l}\text { Tipo de } \\
\text { vacina }\end{array}$ & $\begin{array}{l}\text { Dose } \\
\text { (ml) }\end{array}$ & $\begin{array}{l}\text { Node } \\
\text { doses }\end{array}$ \\
\hline 6 - 35 meses & SPLIT & 0,25 & $1-2^{*}$ \\
\hline $3-8$ anos & SPLIT & 0,5 & $1-2 *$ \\
\hline $9-12$ anos & SPLIT & 0,5 & 1 \\
\hline$>12$ anos & $\begin{array}{l}\text { SPLIT ou } \\
\text { Vírus total }\end{array}$ & 0,5 & 1 \\
\hline
\end{tabular}

pelo HIV é, pelo menos, 3 vezes menor do que em indivíduos normais, especialmente quando a contagem de linfócitos T CD4+ é inferior a 200/ $\mathrm{mm}^{38}$. Steinhoff Jr. e col. ${ }^{69}$ (1991) demonstraram que em indivíduos assintomáticos, obtêm-se melhor resposta com as vacinas conjugadas, enquanto nos sintomáticos, a vacina não conjugada é mais imunogênica. Todavia, deve-se ressaltar que a vacina não conjugada não estimula a memória dependente de células $\mathrm{T}$ e, portanto, não se conhecem a eficácia e a duração da proteção. Em crianças HIV-positivas, sintomáticas ou não, recomenda-se o mesmo esquema vacinal indicado para crianças normais. Após os 15 meses, a vacina é recomendada em dose única e ainda não existem estudos sobre a necessidade da aplicação de reforços da vacina contra o Hib em crianças e adultos infectados pelo HIV ${ }^{38,58,69}$.

\section{VACINAS CONTRA IN FLU ENZA}

Em geral, as vacinas contra influenza são recomendadas apenas para os mesmos grupos de risco que a vacina antipneumocócica, porém, a vacina purificada do tipo split pode ser administrada a crianças maiores de 6 meses, enquanto a vacina contra pneumococos é contra-indicada para os menores de 2 anos de idade (Tabela 3) ${ }^{4}$. Embora a AAP também recomende a vacina contra a influenza para asmáticos, estima-se que a aplicação da vacina nesse grupo de indivíduos seja baixa. Entre os prováveis motivos para a pequena utilização dessa vacina em asmáticos estão o uso terapêutico de corticoesteróides e o risco de a vacina desencadear crises de broncoespasmo; todavia, já foi demonstrado que a vacina contra influenza não aumenta o risco de broncoespasmo e que sua imunogenicidade é boa em crianças e adultos asmáticos, mesmo quando estão recebendo corticoterapia em doses não imunossupressoras 4, 9, 44, 55 .

Considera-se que a vacina contra influenza é segura em imunodeprimidos, embora apresente menor imunogenicidade ${ }^{2-5,8,9,20}$. Mauch e col.49 (1995) demonstraram que o uso de predinisona em doses não imunossupressoras também não interfere com a imunogenicidade dessa vacina em crianças submetidas a transplantes, quando vacinadas entre 3,4 meses e 10, 6 anos após transplante.

Para diminuir a chance de infecção pelo vírus da influenza, a AAP preconiza a vacinação de todas as pessoas maiores de 6 meses de idade que têm contato íntimo com imuno-deprimidos, incluindo os profissionais de saúde ${ }^{4}$.

Apesar de diversos estudos terem comprovado a segurança da vacina contra a influenza em imunodeprimidos, recentemente foi demonstrado aumento transitório na replicação do HIV, através do PCR, em indivíduos HIV-positivos assintomáticos que receberam essa vacina ${ }^{53}$. Como não existem estudos sobre os riscos da influenza em infectados pelo HIV, discute-se se não seria mais indicada a profilaxia com drogas antivirais para os portadores do HIV, ao invés da vacinação ${ }^{4,5,8,53}$.

\section{VACINA CONTRA MENINGOCOCOS}

A vacina quadrivalente contra meningococos (A, C, Y e W135) é recomendada para os imunodeprimidos e portadores de asplenia anatômica ou funcional, após os 2 anos de idade, porém, sua eficácia e a necessidade de reforços não estão estabelecidas nestes grupos. A vacina monovalente contra meningococos do grupo Aé imunogênica para crianças normais, a partir dos 3 meses de idade, podendo ser administrada quando existir risco de epidemias; entretanto, a resposta imunológica em crianças é inferior à obtida em adultos, sendo recomendadas duas doses (intervalo de 3 meses) quando a vacina for administrada em crianças menores de 18 meses. As vacinas contra meningococos são utilizadas por via IM e, nos grupos de risco, recomenda-se administrar dose de reforço a cada $5 \operatorname{anos}^{2,9}$.

\section{VACINA CONTRA VARICELA}

Apesar de ser considerada uma doença relativamente benigna da infância, anualmente ocorrem mais de 60 milhões de casos de varicela no mundo. Estima-se que, apenas nos Estados Unidos, entre 5.000 e 9.000 crianças sejam hospitalizadas a cada ano. As complicações da varicela são mais frequientes em lactentes jovens, adultos (especialmente idosos) e nos imunodeprimidos, porém, em números absolutos, a maioria das pessoas hospitalizadas em função das complicações da varicela é constituída por crianças previamente saudáveis 9,16,57. Por este motivo, a vacina foi licenciada para uso rotineiro no Japão, Coréia, Estados Unidos e Alemanha. A vacina con- 
tém vírus vivos atenuados e é recomendada para todas as crianças com idade entre 12 e 18 meses de vida, na dose de $0,5 \mathrm{ml}$, por via subcutânea; adolescentes e adultos jovens suscetíveis devem receber duas doses da vacina com intervalo entre 4 e 12 semanas. Apesar de ser bastante segura e imunogênica quando administrada a indivíduos normais, os imunodeprimidos apresentam maior risco de exantema e de disseminação do vírus vacinal; além disso, mais de $50 \%$ dos imunodeprimidos apresentam febre quando estão recebendo quimioterapia. Por esses motivos, embora a vacina tenha sido desenvolvida inicialmente para a prevenção da varicela em imunodeprimidos, e seja indicada para este grupo em diversos países europeus, a AAP e o ACIP não preconizam seu uso em imunodeprimidos (imunodeficiências congênitas, leucemias, linfomas, infecção pelo HIV, doenças malignas e terapia imunossupressora) ${ }^{16,36}$.

Apesar de ser contra-indicada para imunodeprimidos, já foi demonstrado que a administração de duas doses da vacina contra a varicela é segura e imunogênica em crianças com leucemia linfocítica aguda, quando administrada em duas doses, se a doença estiver em remissão há pelo menos um ano, a quimioterapia já tiver sido suspensa e a contagem linfocitária e plaquetária estiverem acima de 700/ $\mathrm{mm}^{3}$ e $100.000 / \mathrm{mm}^{3}$, respectivamente, na data da vacinação. A vacina é capaz de proteger as crianças não apenas contra a varicela, mas, também, contra o zoster. Entretanto, como as crianças leucêmicas apresentam maior incidência de eventos adversos após a vacinação, esta vacina só está liberada nos Estados Unidos para instituições que seguem rígidos protocolos de pesquisa ${ }^{16,32,33,36}$. No Brasil, Cristófani e col. ${ }^{22}$ (1991) demonstraram que a aplicação de uma dose da vacina contra a varicela em 48 crianças com câncer, antes do início da quimioterapia, foi imunogênica e conferiu boa proteção contra a doença, mesmo após contato domiciliar. As crianças que responderam à vacinação apresentaram poucos efeitos adversos e, em 77\% dos vacinados demonstrou-se que os anticorpos permaneceram elevados até dois anos após a vacinação. Todavia, enquanto a vacina contra varicela não for liberada para uso em imunodeprimidos, a melhor profilaxia será a vacinação de todos os contatos domiciliares e profissionais que não tenham tido varicela e que possam transmitir a doença para os imunodeprimidos ${ }^{36}$.

Como a vacina contra varicela contém vírus vivos atenuados, existe a preocupação com a possibilidade de um indivíduo normal vacinado transmitir o vírus vacinal a um imunodeficiente; todavia, a transmissão do vírus vacinal está diretamente relacionada ao número de lesões cutâneas e os indivíduos normais raramente apresentam estas lesões (menos de 10\%). Se um indivíduo vacinado contra a varicela desenvolver lesões cutâneas, deverá evitar o contato com imunodeprimidos durante o período de exantema, entretanto, se o contato ocorrer, o risco de transmissão é baixo e a doença é leve. Os imunodeprimidos vacinados, quando desenvolvem exantema também podem transmitir a doença a seus contatos domiciliares, mas, nesta situação, a varicela é modificada, geralmente, não acompanhada de

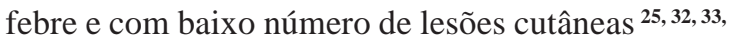
$45,71,75$.

\section{USO DE IMUNOGLOBULINASEM IMUNODEPRIMIDOS}

A imunoglobulina normal é recomendada para todo indivíduo com imunodepressão grave exposto ao sarampo, independentemente de seu estado prévio de vacinação. A dose preconizada é o dobro da dose habitual $(0,5 \mathrm{ml} / \mathrm{kg}$ de peso, máximo $15 \mathrm{ml})$, sendo desnecessária quando o indivíduo está sendo tratado com imunoglobulina endovenosa.

A imunoglobulina específica contra varicelazoster (VZIG) deve ser administrada aos imunodeprimidos expostos à varicela (contato domiciliar ou em ambientes fechados por mais de uma hora). As outras imunoglobulinas específicas contra hepatite B, tétano e raiva são preconizadas nas mesmas doses e esquemas indicados para pessoas normais ${ }^{3,4,8,9}$. 


\section{REFERÊNCIAS}

1. ADENYI-JONES, S.C.A.; FADEN, H.; FERDON, M.B.; KWONG, M.S.; OGRA, P. L. Systemic and local immune responses to enhanced-potency inactivated poliovirus vaccine in premature and term infants. J. Pediatr, 120: 6869, 1992.

2. ADVISORY COMMITTEE ON IMMUNIZATION PRACTICES (ACIP) Recommendations of the Advisory Committee on Immunization Practices (ACIP): use of vaccines and immune globulins for persons with altered immunocompetence. MMWR Morb. Mortal. Wkly Rep., 42 (RR-4): 1-18,1993.

3. ADVISORY COMMITTEE ON IMMUNIZATION PRACTICES (ACIP). General recommendations on immunizations: recommendations of the Advisory Committee on Immunization Practices (ACIP). MMWR Morb. Mortal. Wkly Rep., 43 (RR -1): 1-38,1994.

4. ADVISORY COMMITTEE ON IMMUNIZATION PRACTICES (ACIP). Prevention and control of influenza: recommendations of the Advisory Committee on Immunization Practices (ACIP). MMWR Morb. Mortal. Wkly Rep., 45: 1-23, 1996.

5. ADVISORY COMMITTEE ON IMMUNIZATION PRACTICES (ACIP). Update: vaccine side effects, adverse reactions, contraindications, and precautions. Recommendations of the Advisory Committee on Immunization Practices (ACIP). MMWR Morb. Mortal. Wkly Rep., 45 (RR-12): 135,1996 .

6. AHMED, F.; STEINHOFF, M.C.; RODRIGUEZBARRADAS, M.C.; HAMILTON, R.G.; MUSHER, D.M.; NELSON, K.E. Effect of human immunodeficiency virus type 1 infection on the antibody response to a glycoprotein conjugate pneumococcal vaccine: results from a randomized trial. J. Infect. Dis., 173: 83-90, 1996.

7. ALBUQUERQUE, V.E.; COSTA, M.T.Z.; OKAY, Y. Transmissão vertical do vírus da imunodeficiência humana. Pediatria S. Paulo, 19:57-64, 1997.

8. AMATO, J.G.P.; LOPES, M.H.; AMATO, V.S.; AMATO NETO, V. Imunizações em infectados pelo vírus da imunodeficiência humana (HIV). São Paulo, Balieiro, 1997.

9. AMERICAN ACADEMY OF PEDIATRICS. Red Book: Report of the Committee on Infectious Diseases. 24 ed. Elk Grove Village IL, 1997.

10. ARPADI, S.M.; BACK, S.; O’BRIEN, J.; JANOFF, E. Antibodies to pneumococcal capsular polysaccharides in children with human immunodeficiency virus infection given polyvalent pneumoccoccal vaccine. J. Pediatr., 125: 77-9, 1994.

11. BERNBAUM, J.C.; DAFT, A.; ANOLIK, R.; SAMUELSON, J; BARKIN, R.; DOUGLAS, S; POLIN, R. Response to preterm infants to diphtheria-tetanus- pertussis immunizations. J. Pediatr., 107: 184-8, 1985.

12. BERNBAUM, J.C.; DAFT, A.; SAMUELSON, S.; POLIN R. Half-dose immunization for diphtheria, tetanus, pertussis: response of preterm infants. J. Pediatr., 83: 471-8, 1989.
13. BESNARD, M.; SAUVION, S.; OFFREDO, C.; GAUDELUS, J.; GAILLARD, J.L.; VEBER, F.; BLANCHE, S. Bacillus Calmette-Guérin infection after vaccination of human immunodeficiency virus-infected children. Pediatr. Infect. Dis. J., 12: 993-7, 1993.

14. BORKOWSKY, W.; STEELE, C.J.; GRUBMAN, S.; MOORE, T.; La RUSSA, P.; KRASINSKI, K. Antibody responses to bacterial toxoids in children infected with human immunodeficiency virus. J. Pediatr., 110: 563-6, 1987.

15. BRICKS, L.F. Vacina antipneumocócica: eficácia em diferentes grupos de risco e recentes avanços no desenvolvimento de uma vacina mais imunogênica: atualização. J. Pediatr, 70: 75-81, 1994.

16. BRICKS, L.F. \& RESEGUE, R. Vacina contra varicelazoster: nova perspectiva de controle para uma antiga doença. Pediatria S. Paulo, 18: 134-45, 1996.

17. BRICKS, L.F. Poliomielite: situação epidemiológica e dificuldades para a erradicação global. Pediatria S. Paulo, 19:26- 37, 1997

18. CASANOVA, J.L.; JOUANGUY, E.; LAMHAMED, S; BLANCHE, S; FISCHER, A. Immunological conditions of children with disseminated BCG infection. Lancet, 346: 581, 1995.

19. CASANOVA, J.L.; BLANCHE, S.; EMILE, J.F.; JOUANGUY, E.; LAMHAMED, S.; ALTARE, F.; STÉPHAN, J.L.; BERNAUDIN, F.; BORDIGONI, P.; TURK, D.; LACHAUX, A; ALBERTINI, M.; BOURRILLON, A; DOMMERGUES, J.P.; POCIDALO, M.; LeDEIST, F; GAILLARD, J.L.; GRISCELLI, C.; FISCHER, A. Idiopathic disseminated bacillus CalmetteGuérin infection: a French national restrospective study. Pediatrics, 98: 774-8, 1996.

20. CHADWICK, E.G.; CHANG, G.; DECKER, M.D.; YOGEV, R.; DIMICHELE, D.; EDWARDS, K.M.

Serologic response to standard inactivated influenza vaccine in human immunodeficiency virus-infected children. Pediatr. Infect. Dis. J., 13: 206-11, 1994.

21. CHEN, H.L. ; CHANG, M. H.; HSUEN, Y.; NI, Y. H.; HSU, H. Y. ; LEE, P. I. ; LEE; C. Y.; CHEN, D. S. Seroepidemiolgy of hepatitis B virus infection in children. JAMA, 276: 906- 8, 1996.

22. CRISTÓFANI, L.M.; WEINBERG, A.; PEIXOTO, V.; VILLAS BOAS, L.C.; MARQUES, H.H.; MALUF Jr., P.T,; PANNUTI, C.; OSELKA, G. W.; AMATO NETO, V.; ODONE FILHO, V. Administration of live attenuated varicella vaccine to children with cancer before starting chemotherapy. Vaccine, 9: 873- 6, 1991.

23. DECKER, R. H. Diagnosis. In: Zukerman, A. J; Thomas, H.C. Viral hepatitis: scientific basis and clinical management. Edinburgh, Churchill Livingstone, 1993. p.165-84.

24. DIAS, M.H.P.; BRICKS, L.F.; RESEGUE, R.; GUSHIKEN, C.T. Imunização ativa. In: Sucupira, A.C.S.L. et al. coord. Pediatria em consultório. São Paulo. Sarvier, 1996. p.11726.

25. DIAZ, P.S.; AU, D.; SMITH, S.; AMYLON, M.; LINK, M.; 
SMITH,S.; ARVIN, A.M. Lack of transmission of the live attenuated varicella vaccine virus to immunocompromised children after immunization of their sibilings. Pediatrics, 87: 166-70, 1991.

26. EDWARDS, K.M. \& KERNODLE, D.S. Possible hazards of routine bacillus Calmette-Guérin immunization in human immunodeficiency virus-infected children. Pediatr. Infect. Dis. J., 15: 836-8, 1996.

27. EL-RESHAID, K.; AL-MUFTI, S.; JOHNY, K.V.; SUGATHAN, T.N. Comparison of two immunization schedules with recombinant hepatitis $\mathrm{B}$ vaccine and natural immunity acquired by hepatitis B infection in dialysis patients. Vaccine, 12: 223-8, 1994.

28. EVANS, G. Vaccine liability and safety: a progress report. Pediatr. Infect. Dis. J., 15:447-78, 1996.

29. FABRIZI, F; Di FILIPPO, S.; MARCELLI, D.; GUARNORI, I.; RAFFAELE, L.; CREPALDI, M.; ERBA, G.; LOCATELLI, F. Recombinant hepatitis B vaccine use in chronic hemodialysis patients. Nephron, 72: 536-43, 1996.

30. FEDSON, D.S. \& MUSHER, D.M. Pneumococcal vaccine. In: Plotkin, S.A.; Mortimer, E.A. Vaccines. 2nd.ed. Philadelphia, W.B. Saunders, 1994. p. 517-53.

31. FIÇIOGLU, C.; MIKLA, S.; MIDILLI, K.; AYDIN, A.; ÇAM, H.; ERGIN, S. Reduced immune response to hepatitis B vaccine in children with insulin dependent diabetes. Acta Paediatr. Jpn., 37: 687-90, 1995.

32. GERSHON, A.A.; LaRUSSA, P.; STEIMBERG, S. Clinical trials in immunocompromised individuals. Infect. Dis. Clin. North Am., 10: 583-93, 1996.

33. GERSHON, A.A.; LaRUSSA, P.; STEIMBERG, S.; MERVISH, N.; LO, S.H.; MEIER, P. The protective effect of immunologic boosting against zoster: an analysis in leukemic children who were vaccinated against chickenpox. J. Infect. Dis., 173: 450-3, 1996.

34. GO, E.S. \& BALLAS, Z.K. Anti-pneumococcal antibody response in normal subjects: a meta-analysis. J. Allergy Clin. Immunol., 98: 205-15, 1996.

35. GONZALES, B.; MORENO, S.; BURDACH, R.; VALENZUELA, M.T.; HENRIQUEZ, A.; RAMOS, M.E.; SORENSEN, R.U. Clinical presentation of Bacillus Calmette-Guérin infections in patients with immunodeficiency syndromes. Pediatr. Infect. Dis. J., 8: 201-6, 1989.

36. HOLMES, S.J. Review of recommendations of the Advisory Committee on Immunization Practices, Centers for Disease Control and Prevention, on varicella vaccine. $J$. Infect. Dis., 174 (Suppl 3): S342-4, 1996.

37. HOVI, L.; VALLE, M.; SIIMES, M.A.; JALANKO, H.; SAARINEN, U.M. Impaired response to hepatitis B vaccine in children receiving anticancer chemotherapy. Pediatr. Infect. Dis. J., 14: 931-5, 1995.

38. KALE, K.L.; KING, J.C.; FARLEY, J.J.; VINK, P.E.; CIMINO, C.O.; PARADISO, P. The immunogenicity of Haemophilus influenzae type $\mathrm{b}$ (HbOC) vaccine in human immunodeficiency virus-infected and uninfected infants.
Pediatr. Infect. Dis. J., 14: 350-4, 1995.

39. KAPLAN, J.E.; HU, D.J.; HOLMES, K.K.; JAFFE, H.W.; MASUR, H.; COCK, K.M. Preventing opportunistic infections in human immunodeficiency virus-infected persons: implications for the developing world. Am. J. Trop. Med. Hyg., 55:1-11, 1996.

40. KIM, S.C.; CHUNG, E.K.; HODINKAM, R.L.; DeMAIO, J.; WEST, D.J.; JAWAD, A.F.; WATSON, B. Immunogenicity of hepatitis B vaccine in preterm infants. Pediatrics, 99: 534-6, 1997.

41. KING Jr., J.C.; VINK, P.E.; FARLEY, J.J.; PARKS, M.; SMILIE, M.; MADORE, D.; LICHENSTEIN, R.; MALINOSKY, F. Comparison of the safety and immunogenicity of a pneumococcal conjugate with a licensed polysaccharide vaccine in human immunodeficiency virus and non-human immunodeficiency virus-infected children. Pediatr. Infect. Dis. J., 15: 192-6, 1996.

42. KING Jr., J.C.; VINK, P.E.; FARLEY, J.J.; SMILIE, M.; PARKS, M.; LICHENSTEIN, R.; MALINOSKY, F. Safety and immunogenicity of three doses of a five-valent pneumococcal conjugate vaccine in children with and without human immunodeficiency virus infection. Pediatrics, 99: 575-80, 1997.

43. KRISTENSEN, K.; GYHRS, A.; LAUSEN, B.; BARINGTON, T.; HEILMANN, C. Antibody response to Haemophilus influenzae type b capsular polysaccharide conjugated to tetanus toxoid in preterm infants. Pediatr. Infect. Dis. J., 15: 525-9, 1996.

44. KUBIET, M.A.; GONZALEZ-ROTHI, R.J.; COTTEY, R.; BENDER, B.S. Serum antibody response to influenza vaccine in pulmonary patients receiving corticoesteroids. Chest, 110: 367-70, 1996

45. LaRUSSA, P.; STEINBERG, S.; GERSHON, A. Varicella vaccine for immunocompromised children: results of collaborative studies in the United States and Canada. $J$. Infect. Dis., 174 (Suppl. 3): S320-3, 1996.

46. LAU,Y.L.; TAM, A.Y.C.; NG, K.W.; TSOY, N.S.; LAM, B.; LAM, P, YEUNG, C.Y. Response of preterm infants to hepatitis B vaccine. J. Pediatr., 121: 962-5, 1992.

47. LEE, C.L. \& KO, Y.C. Hepatitis B vaccination and hepatocellular carcinoma in Taiwan. Pediatrics, 99: 351-3, 1997.

48. LEE, H.J.; KANG, J.H.; HENRICHSEN, J.; KONRADSENM, H.B.; JANG, S.H.; SHIN, H.Y.; AHN, H.S.; CHOI, Y.; HESSEL, L.; NAM, S.W. Immunogenicity and safety of a 23 -valent pneumococcal polysaccharide vaccine in healthy children and in children at increased risk of pneumococcal infection. Vaccine, 13: 1533-8, 1995.

49. MAUCH, T.J.; CROUCH, N.A.; FREESE, D.K.; BRAUNLIN, E. A.; DUNIN, D.L.; KASHTAN, C.E. Antibody response of pediatric solid organ transplant recipients to immunization against influenza virus. $J$. Pediatr., 127: 957-60, 1995.

50. MURRAY, C.J.L. \& LOPEZ, A.D. Mortality by cause for eight regions of the world: global burden of disease study. Lancet, 349: 1269-76, 1997. 
51. NINANE, J.; GRYMONPREZ, A.; BURTONBOY, G.; FRANCOIS, A.; CORNU, G. Disseminated BCG in HIV infection. Arch. Dis. Child, 63: 1268-9, 1988.

52. NURSOY, M. A.; BAKIR, M.; BARLAN, I.B.; BASARAN, M. M. The course of chickenpox in asthmatic children receiving inhaled budsonide. Pediatr. Infect. Dis. J., 16: 74$5,1997$.

53. O'BRIEN, W.A.; GROVIT-FERBAS, K.; NAMAZI, A.; OVCAK-DERZIC, S.; WANG, H.J.; PARK, J.; YERAMIAN, C.; MAO, S.H.; ZACK, J. Human immunodeficiency virus type-1 replication can be increased in peripheral blood of seropositive patients after influenza vaccination. Blood, 86: 1082-9, 1995.

54. OSHITANI, H.; SUZUKI, H.; MPABALWANI, M.E.; MIZUTA, K.; NUMAZAKI, Y. Measles case fatality by sex, vaccination status, and HIV-1 antibody in Zambian children. Lancet, 348: 415, 1996.

55. PARK, C.L.; FRANK, A.L.; SULLIVAN, M.; JINDAL, P.; BAXTER, B.D. Influenza vaccination of children during acute asthma exacerbation and concurrent predinisone therapy. Pediatrics, 98 (2 Pt 1): 196-200, 1996.

56. PETERS, V.B. \& SOOD, S. Immunity to Haemophilus influenzae type $\mathrm{b}$ polysaccharide capsule in children with human immunodeficiency virus infection immunized with a single dose of Haemophilus vaccine. J. Pediatr., 125:74-7, 1994.

57. PETERSON, C.L.; MASCOLA L.; CHAO, S.M.; LIEBERMAN, J.M.; ARCINUE, E.L.; BLUMBERG, D.A.; KIM, K.S.; KOVACS, A.; WONG, V.K.; BRUNNEL, P.A. Children hospitalized for varicella: a prevaccine review. $J$. Pediatr., 129: 529-36, 1996.

58. PICHICHERO, M. E.; SHELLY, M.A.; TREANOR, J. J. Evaluation of a pentavalent conjugated pneumococcal vaccine in toddlers. Pediatr. Infect. Dis. J., 16: 72-4, 1997.

59. RESEGUE, R.; BRICKS, L.F.; RODRIGUES, D. Vacina anti Haemophilus influenzae tipo b (Hib): atualização. Pediatria S. Paulo, 16: 176-85, 1994.

60. RODRIGUES, D.; BRICKS, L.F. ; RESEGUE, R. Hepatite B: imunização universal. Pediatria S. Paulo, 18: 82-90, 1996.

61. RODRIGUEZ-CRÉIXEMS, M.; MUÑOZ, P.; MIRANDA, E.; PELÁEZ, T.; ALONSO, R.; BOUZA, E. Recurrent pneumococcal bacteremia. A warming of immunodeficiency. Arch. Intern. Med., 156: 1429-34, 1996.

62. RUDY, B.J.; RUTSTEIN, R.M.; PINTO-MARTIN, J. Responses to measles immunization in children infected with human immunodeficiency virus. J. Pediatric., 125:724,1994 .

63. RYDER, RW.; OXTOBY, M.J.; MVULA, M.; BATTER, V.; BAENDE, E.; NSA, W.; DAVACHI, F.; HASSIG, S.; ONORATO, I.; DEFOREST, A.; KASHAMUKA, M.; HEYWARD, W.L. Safety and immunogenicity of bacille Calmette-Guérin, diphtheria-tetanus-pertussis, and oral polio vaccines in newborn children in Zaire infected with human immunodeficiency virus type 1.J. Pediatr.,122:697-702, 1993.

64. SATO, H.K. Eventos adversos pós-BCG em crianças com AIDS. São Paulo, 1994.[Dissertação de Mestrado-Faculdade de Medicina da Universidade de São Paulo].

65. SKINNER, R.; APPLETON, A.L.; SPROTT, M.S.; MAGEE, J.G.; DARBYSHIRE, P.J.; ABINUN, M.; CANT, A.J. Disseminated BCG infection in severe combined immunodeficiency presenting with severe anaemia and associated with gross hypersplenism after bone transplantation. Bone Marrow Transpl., 17: 877-80, 1996.

66. SMOLEN, P.; BLAND, R.; HEILIGENSTEIN, E.; LAWLESS, M.R.; DILLARD, R.; ABRAMSON, J. Antibody response to oral polio vaccine in premature infants. J. Pediatr., 103: 917-9, 1983.

67. SPIKA, J.S.; HALSEY, N.A.; FISH, A.J.; LUM, G.M.; LAUER, B.A.; SCHIFFMAN, G.; GIEBINK, S. Serum antibody response to pneumococcal vaccine in children with nephrotic syndrome. Pediatrics, 69: 219-23, 1982.

68. STANLEY, S.K.; OSTROWSKY, M.A.; JUSTEMENT, J.S.; GANTT, K.; HEDAYAT, S.; MANNIX, M.; ROCHE K.; SCHWARTZENTRUBER, D.J.; FOX, C.H.; FAUCI, A. Effect of immunization with a common recall antigen on viral expression in patients infected with human immunodeficiency virus type 1. N. Engl. J. Med., 334:1222-30, 1996.

69. STEINHOFF. M.C. ; AUERBACH, B.S.; NELSON, K.E. ; VLAHOV, D.; BECKER, R.L. ; GRAHAM, N.M.H. ; SCHWARTZ, D.H. ; LUCAS, A.H.; CHAISSON, R.E. Antibody responses to Haemophilus influenzae type b vaccines in men with human immunodeficiency virus infection. N. Engl. J. Med., 325: 1837-42, 1991.

70. STEPHAN, J.L.; VLEKOVA, V.; Le DEIST, F. Severe combined immunodeficiency: a retrospective single-center study of clinical presentation and outcome in 117 patients. $J$. Pediatr, 123: 564-72, 1993.

71. TSOLIA, M.; GERSHON, A. A.; STEINBERG, S.P.; GELB, L.; NATIONAL INSTITUTE OF ALLERGY AND INFECTIOUS DISEASES VARICELLA VACCINE COLLABORATIVE STUDY GROUP. Live attenuated varicella vaccine: evidence that the virus is attenuated and the importance of skin lesions in transmission of varicella zoster virus. J. Pediatr, 116:184-9, 1990.

72. VAN DEUTEKOM, H.; SMULDERS,Y.M.; ROOZENDAAT, K.J.; VAN SOOLINGEN, D. Bacille Cal-metteGuérin (BCG) meningitis in an AIDS patient 12 years after vaccination with BCG. Clin. Infect. Dis., 22:870-1, 1996.

73. WASBURN, L.; O'SHEA, T.M.; GILLIS, D.C.; BLOCK, S.M.; ABRAMSON, J.S. Response to Haemophilus influenzae type b conjugate vaccine in chronically ill premature infants. J. Pediatr., 123: 791-4, 1993.

74. WHARTON, M. The epidemiology of varicella-zoster virus infections. Infect. Dis. Clin. N. Am., 10: 571-81, 1996.

75. WELLER, T.H. Varicella: historical perspective and clinical overview. J. Infect. Dis., 174(Suppl. 3): S306-9, 1996. 